Li, X. and Harkness, P. (2021) Ultrasonically assisted coring of rocks. In: IEEE

International Ultrasonic Symposium (IUS 2021), Xi'an, China, 11-16 September 2021, ISBN 9780738112091

(doi: 10.1109/IUS52206.2021.9593485)

This is the Author Accepted Manuscript.

(C) 2021 IEEE. Personal use of this material is permitted. Permission from IEEE must be obtained for all other uses, in any current or future media, including reprinting/republishing this material for advertising or promotional purposes, creating new collective works, for resale or redistribution to servers or lists, or reuse of any copyrighted component of this work in other works.

There may be differences between this version and the published version. You are advised to consult the publisher's version if you wish to cite from it.

$\underline{\text { http://eprints.gla.ac.uk/257497/ }}$

Deposited on: 21 October 2022

Enlighten - Research publications by members of the University of Glasgow http://eprints.gla.ac.uk 


\section{Ultrasonically assisted coring of rocks}

\author{
Xuan Li \\ Centre for Medical \& Industrial Ultrasonics, James Watt School \\ of Engineering \\ University of Glasgow \\ Glasgow, UK \\ Xuan.Li@glasgow.ac.uk
}

\author{
Patrick Harkness \\ Centre for Medical \& Industrial Ultrasonics, James Watt School \\ of Engineering \\ University of Glasgow \\ Glasgow, UK \\ Patrick.Harkness@glasgow.ac.uk
}

\begin{abstract}
Drilling in extreme environments such as extraterrestrial objects allow us to study the original geological and biological signature, and to understand the history hidden beneath. This will require reductions in weight-on-bit, torque and energy usage, without compromising the penetration rateof-progress. This paper examines the use of ultrasonic vibration, directly superimposed onto an augering coring bit, to achieve this goal in aircrete and limestone.

Experimental results show that compared to traditional rotary drilling processes using the same tool, the ultrasonically assisted drilling processes has demonstrated an improved rateof-progress. A total energy consumption is founded at optimum vibration amplitude at the cutting teeth.
\end{abstract}

Keywords-Ultrasonically assisted drilling, weight-on-bit, autonomous control

\section{INTRODUCTION}

Drilling on the surface of extra-terrestrial planets can impose limitations on available weight-on-bit, torque, power, and energy. This low reaction environment is particularly challenging because traditional drilling techniques require large axial forces, high holding torques, and consume a significant amount of power, all of which are incompatible with lightweight spacecraft [1]. Futhermore, traditional techniques are also prone to jamming and bit-walking, which can create problems in autonomous operation of the drill.

To tackle these issues, the ultrasonic/sonic driller/corer (USDC) technology was invented [2]. This technique uses a Langevin-style ultrasonic transducer to excite a percussive stack which consists of a free mass and a free drilling bit, such that percussive pulses can be transmitted through the series chaotic impact between the transducer, free mass and drill bit and then into the rock [3]. The dynamic optimization of the stack is a complex problem [4], and in order to reach a significant depth, technical issues surrounding spoil augering or alternative extraction will still need to be addressed.

Ultrasonically assisted machining (UAM) technology, as an alternative, superimposes high frequency ultrasonic vibrations onto the relative cutting motion between the tool and the target material [5]. This technology has been shown to reduce weight-on-bit, torque, temperature, and tool wear, across a wide range of difficult-to-cut materials [6]-[8] in various industrial machining processes.

However, the application of the UAM technology in rock drilling process remains rare, and although some studies have shown its potential in bits up to $7 \mathrm{~mm}$ diameter [9]-[11], this is the first study to examine the effect when a sizeable drillbit $(21 \mathrm{~mm})$ is managed using an autonomous motion control loop. This work will include an examination of performance in rocks at a range of targeted weights-on-bit and ultrasonic amplitudes, measuring rate-of-progress and total energy consumption, such that any optimum energy settings might be found. The drilling experiments were performed horizontally to avoid any separate spoil augering issues.

\section{ULTRASONIC CORING TOOL AND TEST RIG}

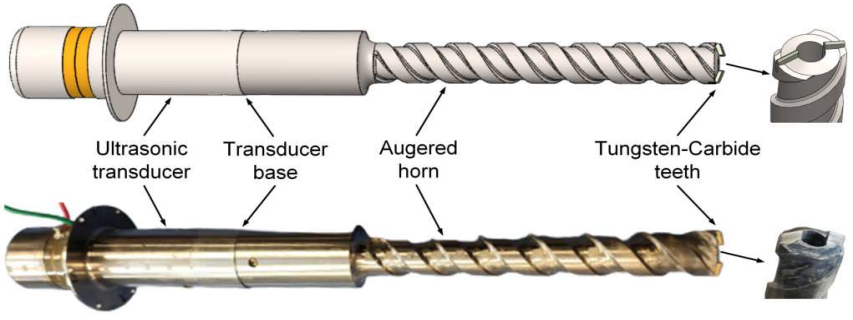

Fig. 1. Ultrasonic coring tool

Fig. 1 presents the ultrasonic coring tool used in this study, made from Ti-6Al-4V alloy. The tool is connected to a Sonic Systems L500 transducer and is energised by a P100 control unit. The horn has a stepped geometry to boost the generated amplitude from the piezoceramic rings stack, and it also has a two-start auger to extract the spoils. Two tungsten carbide teeth were silver brazed into the front slots of the horn [4], but this is known to be a difficult technique with Titanium [12], and tooth failure could potentially be noted as a consequence.

The outer diameter of the coring bit is $21 \mathrm{~mm}$, and the central hollow hole diameter is $8.5 \mathrm{~mm}$, with a depth of 180 $\mathrm{mm}$. The drill tool is tuned to resonate at its $3^{\text {rd }}$ longitudinal mode (L3), at around $20 \mathrm{kHz}$.

The ultrasonic drill tool system is shown in Fig. 2. The drill tool is fitted in a housing at its nodal flange, which is free to rotate and equipped with a spur gear. A pinion gear is fixed to a Maxon DC geared motor (576 rpm, $0.9 \mathrm{Nm}$ maximal torque, Sachseln, Switzerland) to drive the spur gear. The gear ratio is $1: 2.5$, which provides a $190 \mathrm{rpm}$ rotation of the tool, and a slip ring (MFS028-P0210-44V, MOFLON, Shenzhen, China) is used to supply electrical energy to the rotating ultrasonic assembly.

The ultrasonic drill tool assembly and housing are driven into rocks by a GLA750-P $100 \mathrm{~mm}$ linear actuator (Gimson Robotics, Bristol, UK), with a load path through a 9321B force sensor and then to a 5015A charge amplifier (Kistler Instruments Ltd, Winterthur, Switzerland) to acquire the weight-on-bit information during drilling.

A benchtop BK9129B DC power supply (B\&K Precision Corporation, Yorba Linda, CA, USA) is used to supply power to the motor and linear actuator. Power consumption on each channel of the power supply can be recorded through a communication kit (IT-E132B) with the Labview software. 


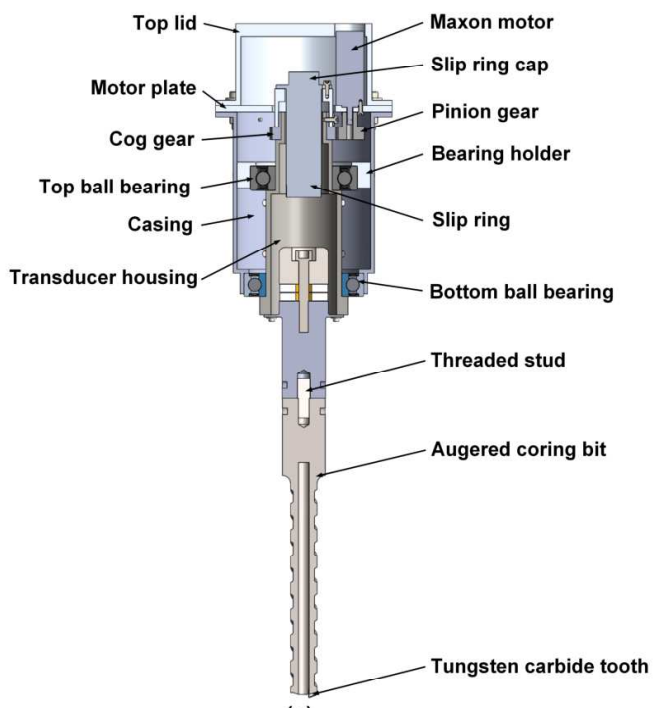

(a)

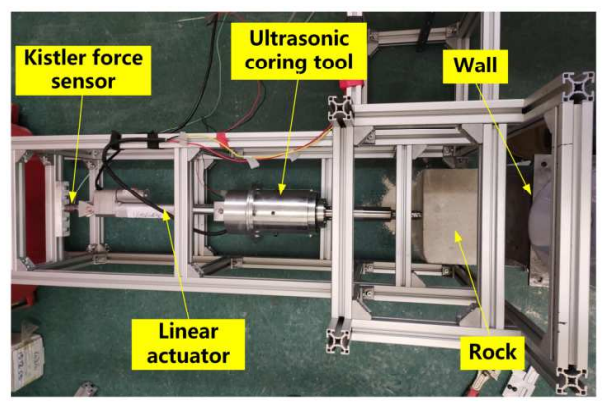

(b)

Fig. 2. Experimental test rig: (a) ultrasonic drill tool assembly, (b) test rig

A feedback motion control system is employed, which is designed to maintain the prescribed weight-on-bit by automatically adjusting the interaction between the drill tool and rock. This is executed by comparing the real-time measured thrust cutting force and the reference weight-onbit, and then command the linear actuator to advance (if the cutting force is far below the target force), not move (if the cutting force is within a dead zone centred of the target force) or retract (if the cutting force is far above the target force).

\section{RESULTS AND DISCUSSION}

\section{A. Vibration analysis}

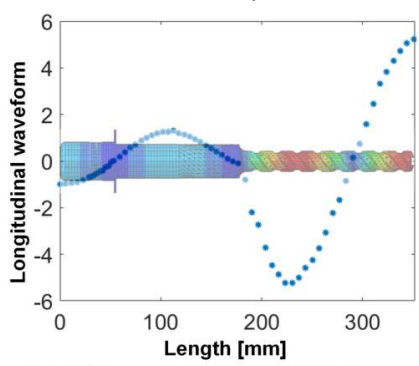

(a) $3^{\text {rd }}$ L-mode FEA $(19840 \mathrm{~Hz})$

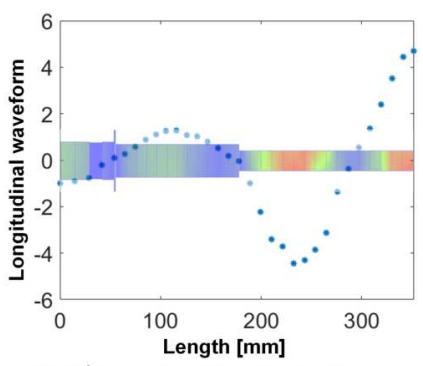

(b) $3^{\text {rd }}$ L-mode EMA $(20108 \mathrm{~Hz})$
Fig. 3. Predicted and measured longitudinal waveform of the ultrasonic drill tool

Fig. 3 presents the predicted and experimentally measured mode shapes of the ultrasonic drill tool. Both waveforms suggest that there are three nodes in the system, located at the transducer flange, at the step, and roughly one- third of the way along the auger section. This confirms that the ultrasonic drill tool will be operated at its third longitudinal mode (L3) at around $20 \mathrm{kHz}$. The gain, defined as the ratio between the amplitude at the teeth and the amplitude at the back mass, shows an agreement of approximately five.

\section{B. Rate of progress}

Target weight-on-bit and displacement amplitude at the cutting teeth were varied during rock drilling experiments.

$0 \mu \mathrm{m}, 2.5 \mu \mathrm{m}, 5.0 \mu \mathrm{m}, 7.5 \mu \mathrm{m}$, and $10 \mu \mathrm{m}$ peak-to-peak amplitude were chosen, which were then generated by the P100 control unit at the base of the transducer (Fig. 1). These correspond to $0 \mu \mathrm{m}, 9.2 \mu \mathrm{m}, 18.2 \mu \mathrm{m}, 27.4 \mu \mathrm{m}$, and $36.6 \mu \mathrm{m}$ amplitudes at the cutting teeth. This gain was confirmed by 1-D laser vibrometer measurements.

For the target weight-on-bit, $50 \mathrm{~N}, 100 \mathrm{~N}$ and $150 \mathrm{~N}$ were selected, allowing the motion control system to be implemented.
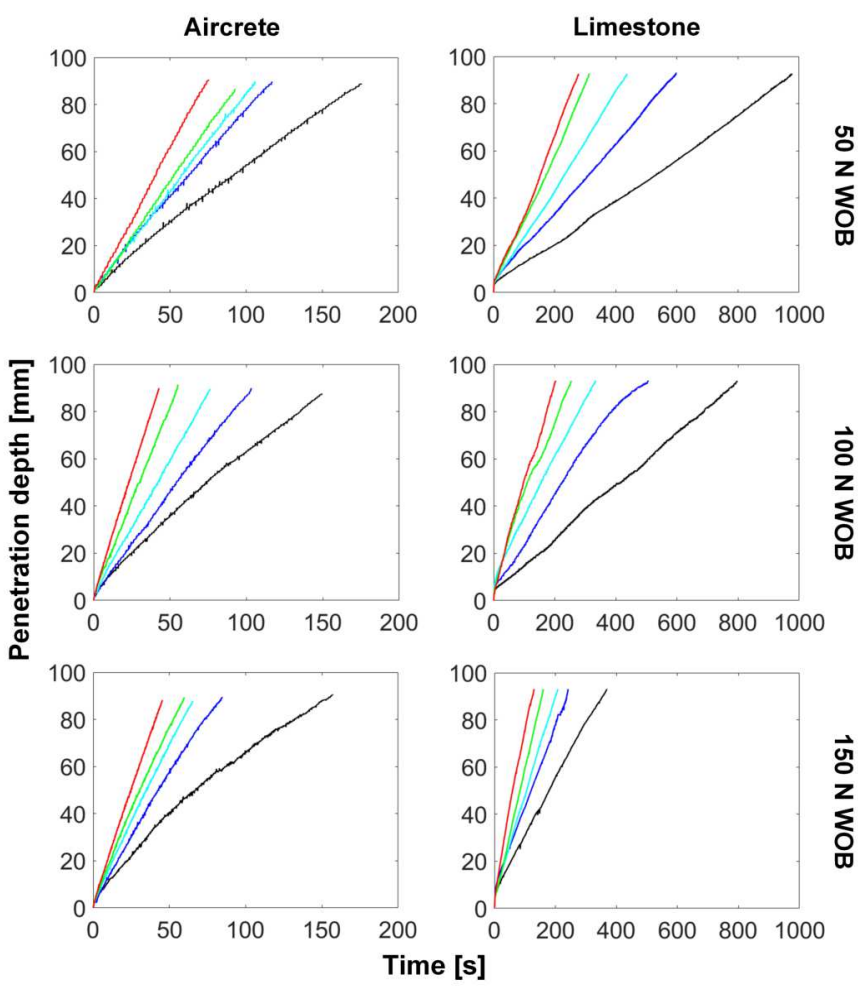

Fig. 4. Penetration depths vs time and weight-on-bit in aircrete and limestone: black $0 \mu \mathrm{m}$, blue $9.2 \mu \mathrm{m}$, cyan $18.2 \mu \mathrm{m}$, green $27.4 \mu \mathrm{m}$, and red $36.6 \mu \mathrm{m}$ amplitude at the teeth

The penetration rate of progress results for aircrete and limestone are shown in Fig. 4.

The ultrasonic drill tool has achieved the maximum depth (approximately $90 \mathrm{~mm}$ ) for all the combination of displacement amplitude and weight-on-bit. The curves are highly linear, with only mild saturation in isolated trials, confirming the consistency of these two rocks material. Both a larger vibration amplitude and an increased weight-on-bit have clearly accelerated the progress in a consistent manner. It takes a significantly longer time to reach to the ultimate depth $90 \mathrm{~mm}$ in limestone with the same amplitude and weight-on-bit than in aircrete, because of the outstanding hardness and compressive strength of limestone. 


\section{Energy density}
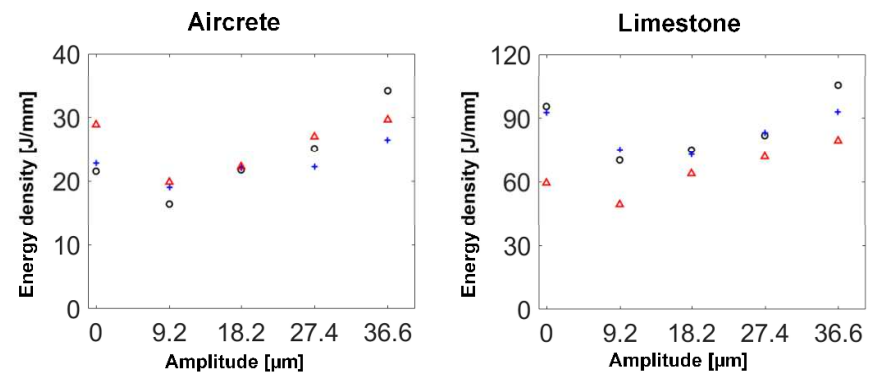

Fig. 5. Rate of progress variation with amplitude and weight-on-bit: $\mathbf{O} 50$ $\mathrm{N}$ weight-on-bit, $+100 \mathrm{~N}$ weight-on-bit, $\Delta 150 \mathrm{~N}$ weight-on-bit

The total energy consumption has been calculated as the aggregation of ultrasonic energy, motor rotation energy and linear actuator motion energy, within the time to reach to the ultimate depth $90 \mathrm{~mm}$ in both aircrete and limestone for all displacement amplitudes and weight-on-bit. A new term "energy density" was then defined as the total energy consumption as per unit penetration depth. Results are shown in Fig. 5.

An energy optimum has been founded for both aircrete and limestone at a $9.2 \mu \mathrm{m}$ amplitude at the teeth for all weight-on-bit. All target weight-on-bit for aircrete have demonstrated minor variations in energy density. However, the $150 \mathrm{~N}$ weight-on-bit has exhibited the least energy density value in limestone, because of the fastest penetration rate of progress (Fig. 4).

\section{CONCLUSION}

This paper presents the preliminary experimental results of the application of an ultrasonically assisted drill tool to different types of rocks, at a range of displacement amplitudes, with an autonomous system maintaining a series of target weights-on-bit.

Results of both aircrete and limestone show near-linear trends, and rate of progress has increased with both weighton-bit $(50 \mathrm{~N}$ to $150 \mathrm{~N})$ and displacement amplitude $(0 \mu \mathrm{m}$ to $36.6 \mu \mathrm{m})$. An amplitude $9.2 \mu \mathrm{m}$ at the tip of the cutting teeth has resulted in the minimal energy consumption per unit depth.

\section{ACKNOWLEDGMENT}

The authors thank University of Glasgow for allowing the research to be carried out in the Hammermen laboratory in James Watt School of Engineering

\section{REFERENCES}

[1] Y. Bar-cohen, S. Sherrit, B. P. Dolgin, X. Bao, Z. Chang, D. S. Pal, R. Krahe, J. Kroh, S. Du, and T. Peterson, "Ultrasonic/sonic drilling/coring (USDC) for planetary applications," Proceedings of SPIE's $8^{\text {th }}$ Annual International Symposium on Smart Structures and Materials, no. 4327-55, pp. 1-7, 2001.

[2] S. Sherrit, B. P. Dolgin, Y. Bar-cohen, D. S. Pal, J. Kroh, and T. Peterson, "Modeling of Horns for Sonic/Ultrasonic Applications," IEEE Ultrasonics Sumposium, 1999.

[3] P. Harkness, M. Lucas, and A. Cardoni, "Maximization of the Effective Impulse Delivered by a High-Frequency/Low-Frequency Planetary Drill Tool," IEEE Transactions on Ultrasonics, Ferroelectrics, and Frequency Control, vol. 58, no. 11, pp. 23872396, 2011.
[4] X. Li, M. Lucas, and P. Harkness, "Full and Half-Wavelength Ultrasonic Percussive Drills," IEEE Transactions on Ultrasonics, Ferroelectrics, and Frequency Control, vol. 65, no. 11, pp. 21502159, 2018.

[5] V. I. Babitsky, V. K. Astashev, and A. N. Kalashnikov, "Autoresonant control of nonlinear mode in ultrasonic transducer for machining applications," Ultrasonics, vol. 42, no. 1-9, pp. 29-35, 2004.

[6] V. K. Astashev and V. I. Babitsky, "Ultrasonic Processes and Machines," Springer-Verlag Berlin Heidelberg, 2007.

[7] V. V. Silberschmidt, S. M. A. Mahdy, M. A. Gouda, A. Naseer, A. Maurotto, and A. Roy, "Surface-roughness improvement in ultrasonically assisted turning," Procedia CIRP, vol. 13, pp. 49-54, 2014.

[8] W. X. Xu and L. C. Zhang, "Ultrasonic vibration-assisted machining: principle, design and application," Advances in Manufacturing, vol. 3, no. 3, pp. 173-192, 2015.

[9] J. Dassow, X. Li, M. R. Lee, M. Young, and P. Harkness, "Ultrasonic drilling for the characterisation of building stones and salt induced decay," Ultrasonics, vol. 101, 2020.

[10] X. Peng, L. Li, Y. Yang, G. Zhao, and T. Zeng, "Experimental study on rotary ultrasonic vibration assisted drilling rock," Advances in Space Research, vol. 67, no. 1, pp. 546-556, 2020.

[11] N. V. Mikhailova, P. Y. Onawumi, A. Roy, and V. V Silberschmidt, "Ultrasonically Assisted Drilling of Rocks," AIP Conference Proceedings, vol. 1959, no. 1, pp. 1-5, 2018.

[12] G. Paulsen, Z. Mank, A. Wang, P. Chow, C. Hyman, T. Thomas, A. Lee, K. Zacny, J. Smith, J. Quinn, E. Mumm, and R. Hayes, "The Regolith and Ice Drill for Exploration of New Terrains (TRIDENT); a One-Meter Drill for the Lunar Resource Prospector Mission," Proceedings of the $44^{\text {th }}$ Aerospace Mechanisms Symposium, pp. 13$25,2018$. 